\title{
Incidence and Prognostic Significance of Myocardial Injury after Elective Percutaneous Coronary Intervention in Duhok, Iraq
}

\author{
Ameen M Mohammad ${ }^{1 *}$, Hartmut K Guelker², Sabri K Sheikhow ${ }^{3}$
}

\author{
'Department of Internal Medicine, College of Medicine, Duhok University, Duhok, Iraq. \\ 2Department of Cardiology, Helios University Hospital Wuppertal, University of Witten/Herdecke, Wupertal, Germany. \\ 3Department of Internal Medicine, College of Medicine, Duhok University, Duhok, Iraq. \\ *Correspondence to: Ameen M Mohammad (E-mail: doctoramb@yahoo.com) \\ (Submitted: 10 July 2021 - Revised version received:02 August 2021 - Accepted: 25 August 2021 - Published online: 26 October 2021)
}

\begin{abstract}
Objectives: This study aims to look at the incidence of myocardial injury after elective percutaneous coronary intervention (PCI) and to correlate its effect to midterm clinical outcome.

Methods: A total of 182 patients were enrolled. Their mean age was (57.44 \pm 9.15$)$ years. They were undergoing elective PCls in Azadi heart center, Duhok, Iraq. Cases with positive cardiac troponin (cTn) pre-procedural were excluded. Within first 24-hours after PCI (cTn) was estimated. And then after all patients were followed for 12 months for major adverse cardiac events (MACE).

Results: 36 (19.8\%) out of 182 (100\%) had elevated cTn. Those patients with elevated cTn had a statistically significant higher rate of prior CABG, ECG changes, triple vessels disease, type C lesions, post stent balloon dilatation and more periprocedural side branch jeopardy and coronary dissections compared to those with negative $c T n(P \leq 0.05)$. During follow up; the MACE was higher in patients with positive $\operatorname{Tn}(\log$ rank $=0.04)$. Conclusion: Minor myocardial injury after elective PCl is common. It's associated with procedural complexity and stratified patients at risks of worse prognosis.

Keywords: Myocardial injury, preprocedural myocardial infarction, elective PCI
\end{abstract}

\section{Introduction}

The prevalence of coronary artery disease (CAD) is high in countries in Africa and the Middle East. According to latest World Health Organization data published in April 2011 cardiovascular diseases account for $25 \%$ of total deaths in Iraq. CAD exclusively account for $14.2 \%$ of total deaths ${ }^{1-5}$.

Medical treatments of CAD have improved in the past decade because of the availability of statins, effective blood pressure lowering drugs and antiplatelet agents. In addition, improvements in PCIs and using of drug eluting stents have revolutionized the management of $\mathrm{CAD}^{6}$. With technological advances in coronary intervention over the past 3 decades, procedural complications and long-term outcomes have significantly improved, yet periprocedural myocardial infarction remains common, with significant therapeutic and prognostic implications ${ }^{7}$.

In the context of PCI, the issue of diagnosing myocardial necrosis and infarction is more complex and controversial. After PCI among patients with a normal baseline troponin value, elevations of cardiac biomarkers above the 99th percentile of the upper reference level are indicative of periprocedural myocardial necrosis ${ }^{8,9}$.

This study aimed to determine the incidence of myocardial injury after elective PCI by the estimation of the cTn and to study the prognostic implications of such elevation to the mid-term clinical outcome of patients in Duhok, Kurdistan, Iraq.

\section{Methods}

Patient Population: During this prospective clinical study a total of 182 cases were recruited. Their ages ranged 33-75 years with a mean age of $(57.44 \pm 9.15)$ years. 109 were males and 93 were females. All cases were undergoing elective stenting for coronary arteries lesions in Azadi heart center in Duhok, Kurdistan region of Iraq. The inclusion criteria were cases of elective PCI with negative pre-procedure cTn. The main exclusion criteria were patients underwent emergency or primary PCI for acute coronary syndrome (ACS), patients with history of ACS within two months and any patients with positive $c$ Tn pre procedure were excluded. The clinical data including demographic, cardiovascular risk factors, and medications were recorded. Electrocardiography, echocardiography, renal function test, screening for hepatitis $\mathrm{B} \& \mathrm{C}$ were done for all patients.

Coronary Angiography and PCl: All patients were receiving dual antiplatelets in addition to other indicated cardiac drugs pre-procedurally. Almost all PCI were performed through the femoral approach. Coronary angiographic lesion characteristics were classified according to American Heart Association/ American College of Cardiology (AHA/ACC) ${ }^{10}$. Successful Procedure was defined as residual stenosis $<30 \%$. Optimization of results by balloon inflations were performed in indicated cases. Peri- and post-procedural complications based on standard definitions were noted ${ }^{11}$. All immediate and in-hospital outcomes related to the procedure through monitoring of all patients inside hospital for up to 24 hours were recorded.

Cardiac Troponin: In pre-procedural period the level of cTn was estimated, and those with negative results were enrolled in the study and underwent PCI with drug eluting stents. Post procedural samples of blood for the estimation of cTn within 24 hours were taken. The cTn was analyzed using a rapid bedside test (Cardiac T, Roche Diagnostics, Mannheim, Germany) with a threshold of (ULN) $0.03 \mathrm{ng} / \mathrm{ml}$.

Follow up for Outcome and MACE: The patients were followed clinically on regular basis for 12 months for MACE and clinical outcome like new onset ischemic attacks specifically acute myocardial infarction, stent thrombosis, ischemic stroke and cardiac death. 22 of our patients were underwent repeated 
(control) coronary angiography for new onset presumed ischemic presentations.

Statistical Analysis: Data were collected and analyzed by using the SPSS software package version ${ }^{22}$. Continuous variables were calculated as mean $\pm(\mathrm{SD})$ and categorical variables were presented as counts and percentages. A chi-square test was used for the comparison of categorical variables. ANOVA test was used for continuous variables. Follow up correlation and cumulative (event free) survival between cardiac troponin and clinical outcome was analyzed by the Kaplan-Meier method and a group comparison was done by the log rank test. A probability value of $\leq 0.05$ was considered statistically significant.

Ethics Approval and Consent to Participate: The study was approved by the ethical committee at the college of medicine, university of Duhok, Iraq and the informed consent was obtained from all enrollees. The study protocol was performed in accordance with the relevant guidelines and regulations of the Declaration of Helsinki.

\section{Results}

Patients Characteristics: Patients with positive cTn had higher incidence of prior CABG and ECG changes compared to group with negative cTn with a significant p- value $(0.02 \&$ $0.03)$ respectively. No significant differences were seen between the two groups in relation to other clinical characteristics and cardiovascular risk factors as shown in Table 1.

Angiographic \& PCI Profile: The group of positive cTn had higher rate of triple vessels disease, type $\mathrm{C}$ lesions compared to other group with a statistically significant difference $(P$-value were 0.05 and $<0.007)$ respectively. Uses of Post stent balloons dilatation were more common in positive cTn group compared to other group with a statistical difference $(P<0.04)$. There were significant differences in term of ECG changes and periprocedural complications including (side branch occlusions and coronary dissections) among patients with positive cTn compared to other group with $P$-value $(0.05,0.03 \& 0.04)$ respectively as shown in Table 2 .

MACE \& Follow up Outcome: There was a significant difference in term of new ECG changes, emergency CABG, MI, needs for repeated coronary angiography and rate of stent thrombosis among group of positive cTn compared to negative cTn group with a $P$-value $(0.01,0.02,0.01,0.01 \& 0.03)$ respectively. One case underwent successful CABG, three cases developed MI due to stent thrombosis (two of them were not complaint to clopidogrel and underwent successful repeated PCI and one with confirmed clopidogrel resistance ${ }^{12}$ ) Table 3.

Kaplan-Meier Survival Curve for cases with positive $(\mathrm{n}=36)$ and negative $(\mathrm{n}=144) \mathrm{cTn}$. It shows a significant difference between two groups regarding the follow up outcome and MACE (Log rank $=0.04)$. There were more complications and cardiac ischemic events during follow up period among patients with positive cTn after elective PCI.

\section{Discussion}

In spite of more than two decades of delivery of PCI services in Iraq, this is the first study, up to our knowledge, of its kind to be done in the country. The main findings of this study are the following: first; myocardial injury especially of minor degree detected by elevation of cTn occurs commonly after elective PCI; second it is more frequent when the PCI-related factors are more complex; third it is associated with worse subsequent cardiac outcome during follow up.

The guidelines of ACC/AHA recommend measurement of cardiac troponin 8-12 hours post-PCI as a class $2 \mathrm{~A}$. Current PCI guidelines give a class I recommendation for the measurement of cardiac biomarkers in patients who have signs or symptoms suggestive of myocardial infarction during

\begin{tabular}{|c|c|c|c|c|c|}
\hline \multicolumn{2}{|l|}{ Characters } & $\begin{array}{c}\text {-ve cTn } \\
146(80.2 \%)\end{array}$ & $\begin{array}{c}\text { +ve cTn } \\
36(19.8 \%)\end{array}$ & $\begin{array}{c}\text { Total } \\
182(100 \%)\end{array}$ & $P$ - value \\
\hline \multicolumn{2}{|l|}{ Age (mean $\pm S D)$} & $56.62 \pm 9.1$ & $58.26 \pm 9.2$ & $57.44 \pm 9.15$ & 0.3 (NS) \\
\hline \multicolumn{2}{|l|}{ Gender (Male) } & 87 (59\%) & $22(61 \%)$ & 109 (59\%) & 0.4 (NS) \\
\hline \multicolumn{2}{|l|}{ Current smoking } & $48(32 \%)$ & $11(30 \%)$ & $59(32 \%)$ & 0.3 (NS) \\
\hline \multicolumn{2}{|l|}{ Hypertension } & $60(41 \%)$ & $15(41 \%)$ & 75 (41\%) & 0.4 (NS) \\
\hline \multicolumn{2}{|l|}{ Hypercholesterolemia } & $47(32 \%)$ & $13(36 \%)$ & $60(32 \%)$ & 0.3 (NS) \\
\hline \multicolumn{2}{|l|}{ Diabetics } & $37(25 \%)$ & $12(33 \%)$ & $49(26 \%)$ & 0.1 (NS) \\
\hline \multicolumn{2}{|l|}{ Prior Ml } & $24(16 \%)$ & $7(19 \%)$ & $31(17 \%)$ & 0.3 (NS) \\
\hline \multicolumn{2}{|l|}{ CHF } & $14(9 \%)$ & $5(2.4 \%)$ & $19(10 \%)$ & 0.2 (NS) \\
\hline \multicolumn{2}{|l|}{ Prior CABG } & $2(1.3 \%)$ & $2(2.4 \%)$ & $4(2 \%)$ & 0.02 \\
\hline \multicolumn{2}{|l|}{ Renal impair } & $6(4 \%)$ & $2(5.5)$ & $8(4.2 \%)$ & 0.3 (NS) \\
\hline \multicolumn{2}{|l|}{ ECG changes } & $65(44 \%)$ & $10(27 \%)$ & 75 (41\%) & 0.03 \\
\hline \multicolumn{2}{|l|}{ RWM abnormalities } & $35(23 \%)$ & $13(36 \%)$ & $48(26 \%)$ & 0.06 (NS) \\
\hline \multirow[t]{4}{*}{ Cardiac medications } & Antiplat. & $146(100 \%)$ & $36(100 \%)$ & $182(100 \%)$ & 0.2 (NS) \\
\hline & Beta-block & $126(86 \%)$ & $30(83 \%)$ & $156(85 \%)$ & 0.3 (NS) \\
\hline & ACE & $58(39 \%)$ & $13(36 \%)$ & 71 (39\%) & 0.3 (NS) \\
\hline & Statin & 146 (100\%) & 36 (100\%) & 182 (100\%) & 0.2 (NS) \\
\hline
\end{tabular}




\begin{tabular}{|c|c|c|c|c|c|}
\hline Characteristics & & $\begin{array}{c}\text {-ve cTn } \\
146(82.2 \%)\end{array}$ & $\begin{array}{c}\text { +ve cTn } \\
36(19.8 \%)\end{array}$ & $\begin{array}{c}\text { Total } \\
182(100 \%)\end{array}$ & $P$-value \\
\hline \multirow[t]{4}{*}{ Vessel disease } & LMS & $3(2 \%)$ & $2(5 \%)$ & $5(2.7 \%)$ & 0.1 (NS) \\
\hline & LAD & 65 (44\%) & $18(50 \%)$ & $83(45 \%)$ & 0.1 (NS) \\
\hline & LCX & 37 (25\%) & $6(16 \%)$ & $43(23 \%)$ & 0.1 (NS) \\
\hline & RCA & $41(28 \%)$ & 10 (27\%) & $51(28 \%)$ & 0.4 (NS) \\
\hline \multirow[t]{3}{*}{ No. of vessels } & Single & 65 (44\%) & $7(19 \%)$ & 72 (39\%) & 0.002 \\
\hline & Double & 44 (30\%) & 15 (41\%) & $59(32 \%)$ & 0.09 (NS) \\
\hline & Triple & 37 (25\%) & $14(40 \%)$ & $51(28)$ & 0.05 \\
\hline \multirow[t]{3}{*}{ Coronary lesion } & Type A & 71 (48\%) & $7(19 \%)$ & 78 (42.8\%) & 0.007 \\
\hline & Type B & 47 (32\%) & $15(41 \%)$ & $62(34 \%)$ & 0.1 (NS) \\
\hline & Type C & $28(20 \%)$ & $14(40 \%)$ & $42(23 \%)$ & 0.005 \\
\hline \multirow[t]{6}{*}{$\mathrm{PCl}$ characteristics } & Lesion length & $22.2 \pm 5.8$ & $23.0 \pm 6.1$ & $22.6 \pm 5.95$ & 0.4 (NS) \\
\hline & No. lesion & $323(2.2 \%)$ & $104(2.8 \%)$ & 427 (2.34\%) & NS \\
\hline & Stent type & DES & DES & DES & - \\
\hline & Stent length & $24.7 \pm 6.1$ & $25.1 \pm 6.3$ & $24.9 \pm 6.2$ & 0.7 (NS) \\
\hline & Stent diameter & $2.80 \pm 0.41$ & $2.88 \pm 0.52$ & $2.84 \pm 0.46$ & 0.3 (NS) \\
\hline & Inflation bars & $13.4 \pm 3.2$ & $13.5 \pm 3.2$ & $13.45 \pm 3.2$ & 0.8 (NS) \\
\hline \multirow[t]{2}{*}{ Balloon dilatation } & Pre & 69 (47\%) & $17(47 \%)$ & $86(47 \%)$ & 0.4 (NS) \\
\hline & Post & $20(13 \%)$ & $9(25 \%)$ & 29 (15.9\%) & 0.04 \\
\hline \multirow[t]{5}{*}{ Complications } & Chest pain & 16 (10.9\%) & $7(19.4 \%)$ & $23(12.6 \%)$ & 0.08 (NS) \\
\hline & ECG changes & $9(6 \%)$ & $5(13 \%)$ & 14 (7.6\%) & 0.05 \\
\hline & S.B occlusion & $5(3 \%)$ & $4(11 \%)$ & $9(4.9 \%)$ & 0.03 \\
\hline & Dissection & $6(4 \%)$ & $4(11 \%)$ & $10(5.4 \%)$ & 0.04 \\
\hline & No reflow & $1(0.6 \%)$ & $1(2 \%)$ & $2(1.09 \%)$ & 0.1 (NS) \\
\hline
\end{tabular}

Table 3. MACE and follow up outcome (censored)

\begin{tabular}{|c|c|c|c|c|c|}
\hline \multicolumn{2}{|c|}{ Cardiac outcome } & $\begin{array}{c}\text {-ve cTn } \\
146(80.2 \%)\end{array}$ & $\begin{array}{c}\text { +ve cTn } \\
36(19.8 \%)\end{array}$ & $\begin{array}{c}\text { Total } \\
182(100 \%)\end{array}$ & $P$-valve \\
\hline \multicolumn{2}{|l|}{ Ischemic symptom } & $18(9 \%)$ & $8(22 \%)$ & $26(14.2 \%)$ & 0.06 (NS) \\
\hline \multicolumn{2}{|l|}{ ECG changes } & $5(3 \%)$ & $5(13 \%)$ & $10(5.4 \%)$ & 0.01 \\
\hline \multicolumn{2}{|l|}{ Non-complaint } & $6(4 \%)$ & $3(8 \%)$ & $9(4.6 \%)$ & 0.1 (NS) \\
\hline \multicolumn{2}{|l|}{ Cardiac death } & $1(0.6)$ & $0(0 \%)$ & $1(0.5 \%)$ & 0.4 (NS) \\
\hline \multicolumn{2}{|l|}{ Emergency CABG } & $0(0 \%)$ & $1(2 \%)$ & $1(0.5 \%)$ & 0.02 \\
\hline \multicolumn{2}{|l|}{ Myocardial infarct } & $1(0.6 \%)$ & $2(5 \%)$ & $3(1.64 \%)$ & 0.01 \\
\hline \multicolumn{2}{|l|}{ Stroke } & $0(100 \%)$ & $0(100 \%)$ & $0(0 \%)$ & - \\
\hline \multicolumn{2}{|l|}{ Control C. Angio } & $14(9 \%)$ & $8(22 \%)$ & $22(12.08 \%)$ & 0.01 \\
\hline \multicolumn{2}{|l|}{ Stent thrombosis } & $1(0.6 \%)$ & $2(5 \%)$ & $3(1.64 \%)$ & 0.03 \\
\hline \multicolumn{2}{|l|}{ ISR } & $1(0.6 \%)$ & $0(0 \%)$ & $1(0.5 \%)$ & 0.4 (NS) \\
\hline \multirow[t]{2}{*}{ Repeated PCl } & Target & $2(1.3 \%)$ & $2(5 \%)$ & $4(2.1 \%)$ & 0.06 (NS) \\
\hline & Denovo & $4(2.7 \%)$ & $2(5 \%)$ & $6(3.2 \%)$ & 0.1 (NS) \\
\hline
\end{tabular}

or after PCI and for those who have undergone complicated procedures $^{13}$.

In this study $36(19.8 \%)$ out of $182(100 \%)$ had elevated cTn. The reported incidence of troponin release after PCI in literature ranges between $13 \%$ and $44 \%$, with the incidence higher after stenting ${ }^{14}$. In Suadia Arabia, a study demonstrated that cTn elevated in (29\%) after elective PTCA. The cTn biomarker is sensitive in detection of even minor myocardial injuries after successful stenting ${ }^{15}$.

There are conflicting findings between studies in term of prognostic significance of myocardial injury. Some studies showed no association between myocardial injury and follow 


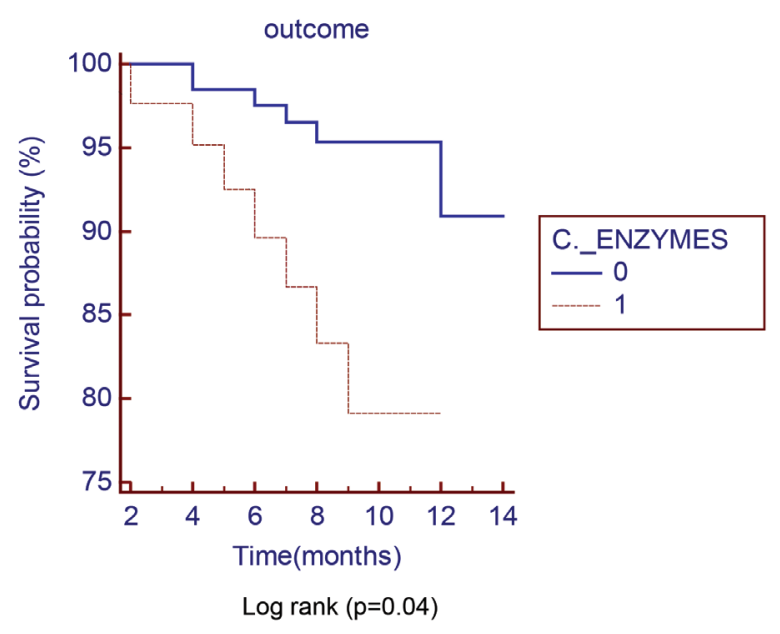

$0=$ negative $\mathrm{cTn}$ group

$1=$ positive $\mathrm{cTn}$ group

MACE $^{16,17}$. However, others found the association ${ }^{18}$. In the present study, the clinical outcome during the follow up was significantly affected in the group of positive cTn. There was a significant increase in the rates of new onset ischemic attacks including new ECG changes, MI, needs for repeated revascularization and stent thrombosis with a $P$-value $(0.01,0.01,0.02$ \& 0.03 ) respectively. A meta-analysis of 15,581 patients in twenty studies was performed by Nienhuis and colleagues found troponin elevation in $32.9 \%$ of the patients and a $1.1 \%$ higher mortality compared with the non-troponin elevated group ${ }^{19-21}$.

There are many possible underlying causes of elevated cTn after stenting; moreover, it was found a significant relation in the present study to the peri-procedural complications like side branch jeopardize, evidence of significant dissections with clinical manifestation like presence of new onset ischemic chest pain and/or ECG changes. Even without clear ischemic clinical features and imaging availability, the cTn measurement after PCI is easy test and helpful for detecting the consequences of distal embolization of proximal platelet-thrombi aggregates during stent implantation as one of the potential hidden cause of patchy myocardial necrosis and injury. Therefore, cTn elevations post procedure could be a valid end-point for clinical trials designed to compare coronary artery disease treatments $\mathrm{s}^{22,23}$.

The implications of this study are important as we shift towards a cTn definition, with fewer dependents on other cardiac biomarkers, for the detection of minor myocardial injury and will require improved standardization of assays and cut-off values. Another point is about one fifth of patients in this study sustained a periprocedural myocardial injury after the procedure when cardiac troponins was used to detect myonecrosis Figure 1.

The limitations of this study included a relatively short follow up time of cases; especially for the monitoring of In-stent restenosis (ISR) which could occurs mainly following balloon dilatations and vascular injury ${ }^{24}$. And secondly marginalize the effect of magnitude of elevation to the clinical profiles and outcome measurements.

Few questions can be derived from the present study that we recommend to be tackled in the future studies; like which kind of patients who sustained periprocedural myocardial injury should be observed for longer time inside the hospital and after discharge. Secondly, from the prognostic point of view, how far the periprocedural myocardial infarction is differing from spontaneous myocardial infarction. Thirdly from ethical point of view what shall we tell the patient who developed periprocedural MI despite a successful procedure ${ }^{25-27}$.

\section{Conclusions}

One out of 5 elective PCIs have sustained myocardial injury. cTn is easy and sensitive biomarker in detecting the injury. In term of prognosis, the injury was associated with MACE during follow up. The occurrence of injury was commonly related to procedure complexity and complications. In consistence with the PCI guidelines we recommend based on our findings to estimate the cTn level after performing elective PCI in cases with prior CABG, new ECG changes, type C lesions, triple vessels disease, side branch jeopardy and coronary dissections in our centers. Closer follow up and adherence to intensive justified treatment of those patients with raised cTn may lead to improving outcomes.

\section{Conflicts of Interest}

The authors declare that there are no conflicts of interest.

\section{Acknowledgment}

We acknowledge the cooperation of staff of Azadi Heart Center in Duhok for their cooperation while doing this study.

\section{Funding/Support}

The authors received no financial support for the publication of this article.

\section{Authors' Contribution}

All authors equally contributed to conducting the study, designing and collecting data, and writing the paper. Further, all authors approved the final review of the manuscript.

\section{References}

1. Almahmeed W, Arnaout MS, Chettaoui R, Ibrahim M, Kurdi MI, Taher MA, Mancia G (2012). Coronary artery disease in Africa and the Middle East. Ther Clin risk Manag. 8:65-72.

2. WHO Report (2011). Cardiovascular disease in Iraq. Website of WHO/IRAQ. Available from: ( http://www.who.int /countries/irq/en/).

3. Mohammad, A.M., Jehangeer, H.I. \& Shaikhow, S.K. Prevalence and risk factors of premature coronary artery disease in patients undergoing

coronary angiography in Kurdistan, Iraq. BMC Cardiovasc Disord 15, 155 (2015). https://doi.org/10.1186/s12872-015-0145-7.

4. Mohammad AM, Sheikho SK, Tayib JM. Relation of Cardiovascular Risk Factors with Coronary Angiographic Findings in Iraqi Patients with Ischemic Heart Disease. Am J Cardiovasc Dis Res. 2013;1(1):25-9.

5. Mohammad AM, Rashad HH, Habeeb QS, Rashad BH, Saeed SY Demographic, clinical and angiographic profile of coronary artery disease in 
kurdistan region of Iraq. Am J Cardiovasc Dis. 2021;11(1):39-45. Published 2021 Feb 15.

6. Seema Pursnani, Frederick Korley, Ravindra Gopaul, Pushkar Kanade, Newry Chandra, Richard E. Shaw et al (2012). Percutaneous coronary intervention versus optimal medical therapy in stable coronary artery disease: A Systematic review and meta-Analysis of randomized clinical trials. Circ Cardiovasc Interv 5:476-490.

7. Alexandra J Lansky, Gregg W. Stone (2010). Periprocedural myocardial infarction: Prevalence, Prognosis, and Prevention. Circ Cardiovasc Interv. 3:602-610.

8. Abhiram Prasad, Joerg Herrmann (2011). Myocardial infarction due to percutaneous coronary intervention. N Engl J Med 364:453-464.

9. Centor, R. M, Jeroan J Allison, Norman W Weissman, John Canto, Gustavo Heudebert, Lucia Juarez, Catarina I Kiefe (2003). Diffusion of troponin testing in unstable angina patients: adoption prior to guideline release. J Clin Epidemiol 56: 1236-1243.

10. Dehmer GJ, Vinay B, Bermudez Edmund A, et al. 2020 AHA/ACC key data elements and definitions for coronary revascularization: a report of the American College of Cardiology/American Heart Association Task Force on Clinical Data Standards (Writing Committee to Develop Clinical Data Standards for Coronary Revascularization). Circ Cardiovasc Qual Outcomes. 2020; 13(4):e000059.

11. Glenn N. Levine, Issam Bailey, John A. Bittl, Bojan Cercek, Charles E, Stephen G. Ellis et al. (2011). Angiography and Interventions Association Task Force on Practice Guidelines and the Society for Cardiovascular Summary: A Report of the American College of Cardiology Foundation/American Heart. Circulation. 2011;124:2574-2609.

12. Mohammad AM, Al-Allawi NA. CYP2C19 genotype is an independent predictor of adverse cardiovascular outcome in Iraqi patients on clopidogrel after percutaneous coronary intervention. J Cardiovasc Pharmacol 2018; 71:347-51.

13. Smith SC Jr, Feldman TE, Hirshfeld JW Jr, Jacobs AK, Kern MJ, King SB III, Morrison DA (2006). ACC/AHA/SCAI 2005 guideline update for percutaneous coronary intervention: a report of the American College of Cardiology/American Heart Association Task Force on Practice Guidelines (ACC/AHA/SCAI Writing Committee to Update 2001 Guidelines for Percutaneous Coronary Intervention). Circulation 113(7):e166-e286

14. Saadeddin S.M, Habbab M.A, Sobki S.H, Ferns G.A (2001). Minor myocardial injury after elective uncomplicated successful PTCA with or without stenting: detection by cardiac troponins. Cathet. Cardiovasc. Interv. 53 (2), 188-192.
15. Salam M. S, Mohommed A. H, Samia H. S, Gordon A. F (2000). Detection of minor myocardial injury after successful percutaneous transluminal coronary angioplasty with or without stenting. Med Sci Monit 6(4):708-712.

16. Garbarz E, lung B, Lefevre G, Makita Y, Farah B, Michaud P, Graine H, Vahanian $A$ (1999). Frequency and prognostic value of cardiac troponin I elevation after coronary stenting. Am. J. Cardiol 84 (5), 515-518.

17. Okmen E, Cam N, Sanli A, Unal S, Tartan Z, Vural M (2006). Cardiac troponin I increase after successful percutaneous coronary angioplasty: Predictors and long term prognostic value. Angiology. 57(2):161-9.

18. Abdelmeguid AE, Topol EJ, Whitlow PL, Sapp SK, Ellis SG (1996). Significance of mild transient release of creatine kinase MB fraction after percutaneous interventions. Circulation 94: 1528-1536.

19. Nienhuis, M.B., Ottervanger, J.P., Bilo, H.J., Dikkeschei, B.D., Zijlstra, F (2008). Prognostic value of troponin after elective percutaneous coronary intervention: a met-analysis. Catheter Cardiovasc. Interv 71 (3), 318-324.

20. Mohammed A. Al-Qtaiby, Hussein S. Al-Amri, Abdulrahman M. Al-Moghairi (2011). The clinical significance of cardiac troponins in medical practice. Journal of the Saudi Heart Association 23, 3-11.

21. Prasad A, Rihal CS, Lennon RJ, Singh M, Jaffe AS, Holmes DR Jr (2008). Significance of periprocedural myonecrosis on outcomes after percutaneous coronary intervention:an analysis of preintervention and postintervention troponin T levels in 5487 patients.Circ Cardiovasc Interv 1:10-9.

22. Michael C. Kontos (2010). Prognostic value of isolated troponin I elevation after percutaneous coronary intervention. Circ Cardiovasc Interv 3(5):431-5.

23. Bahrmann P, Werner GS, Heusch G, Ferrari M, Poerner TC, Voss A (2007). Detection of coronary microembolization by doppler ultrasound in patients with stable angina pectoris undergoing elective percutaneous coronary interventions. Circulation 115:600-8.

24. Tolga Kocum, Mustafa Yurtdas, Turkay Ozcan, Burka Akcay, Tansel Erol, Ahmet Camsari, Oben Doven (2008). Direct stenting versus predilatation and stenting technique when using Paclitaxel-eluting stents. Int Heart J 49(5);545-51.

25. Cavallinin C, Verdecchia P, Savonitto S, et al (2010). Prognostic value of isolated troponin I elevation after percutaneous coronary intervention. Circ Cardiovasc Interv 3 (5):413-5.

26. Dmitriy N. Feldman, Luke Kim, A. Garvey Rene, Robert M. Minutello,Geoffrey Bergman, S. Chiu Wong (2011). Prognostic value of cardiac troponin-I or troponin-T elevation following non-emergent percutaneous coronary intervention: A meta-analysis. Catheterization and Cardiovascular Interventions. 77(7):1020-1030

27. Thygesen K, Alpert JS, Jaffe AS, Simoons ML, Chaitman BR, White HD (2012). Third universal definition of myocardial infarction. Circulation 126:2020-2035. 